\title{
Çay Çalısı Budama Atıkları Kullanılarak Eosin Y Boyarmaddesinin Sulu Çözeltiden Biyosorpsiyonu için İzoterm Verilerinin İncelenmesi
}

\author{
Mehmet KAYA $^{1 *}$ \\ ${ }^{1}$ Recep Tayyip Erdoğan Üniversitesi Fen Edebiyat Fakültesi Kimya Bölümü, Rize, Türkiye
}

Geliş / Received: 29/05/2019, Kabul / Accepted: 20/02/2020

\section{$\ddot{O} \mathbf{z}$}

Bu çalışmada, atık çay çalısından elde edilen düşük maliyetli, bol miktarda bulunan, verimli ve çevre dostu bir biyo-atık, adsorban olarak değerlendirilmiştir. Çevreyi kirleten maddelerin giderimleri için bu çalışmada kullanılan doğal ürün, mevcut pahalı yöntem ve hammaddelerine alternatif olarak sunulmuştur. Eosin Y (EY) sulu çözeltiden adsorpsiyonunda, etkileşim süresi, $\mathrm{pH}$, adsorban miktarı vb. gibi çeşitli parametrelerin etkileri incelenmiş ve optimum deney koşulları ortaya konmuştur. Deneysel sonuçlar ışı̆̆ında, Langmuir izoterm modelinde, $25^{\circ} \mathrm{C}^{\prime} \mathrm{da}$ maksimum adsorpsiyon kapasitesi $3,56 \mathrm{mg} / \mathrm{g}$ olarak hesaplanmıştır. Veriler 1 şı̆̆ı ında Freundlich modelinin deneysel verilerle daha iyi bir uyum sağladığ tespit edilmiştir. Mevcut araştırmalar ve bildirilen diğer adsorbanlarla karşılaştırıldığında, çay çalısının, sulu çözeltiden EY'nin giderilmesi için düşük maliyetli doğal ürün olması sebebiyle, bir seçenek olarak uygulanabileceği sonucuna varılmıştır.

Anahtar Kelimeler: adsorpsiyon, biyosorpsiyon, boyarmadde-giderimi, çay-çalısı, eosin y.

\section{Investigation of Isotherm Data for Biosorption of Eosin Y Dye from Aqueous Solution using Tea Stem Pruning Wastes}

\begin{abstract}
In this study, by evaluating the low-cost, abundant, efficient and environment-friendly bio-waste obtained from the waste of tea stem, it has been ensured that this waste will be an alternative to the current expensive methods and raw materials in terms of the removal of environmental pollutants. Eosin Y (EY) adsorption from the aqueous solution, the effects of various parameters such as adsorbent dosage, interaction time and $\mathrm{pH}$ were investigated and optimum experimental conditions were determined. In the Langmuir isotherm model, experimental results were obtained at a maximum adsorption capacity of $3.56 \mathrm{mg} / \mathrm{g}$ at $25^{\circ} \mathrm{C}$. In the light of the data, it was determined that the Freundlich model is more compatible with the experimental data. It is concluded that tea stem can be applied as an option since it is a low cost and natural product for removing EY from aqueous solution, compared with the present research and other adsorbents reported in the literature.
\end{abstract}

Keywords: adsorption, biosorption, dye-removal, eosin y, tea-stem.

*Sorumlu Yazar: mehmet.kaya@erdogan.edu.tr 


\section{Giriş}

Son y1llarda, dünya genelinde artan endüstriyel ihtiyaçlarla birlikte tüketim ve tüketime bağlı olarak çevre kirliliği de hızla artmaktadır. Başta insan sağlığı olmak üzere bitki ve hayvan ekosistemini de ciddi anlamda olumsuz etkileyen bu duruma karşı insanoğlu sürekli çözüm yöntemleri geliştirmekte ve yeni bilimsel arayıșlara yönelmektedir. Özellikle büyük oranda gelişen Kimya endüstrisinin etkisiyle, çevreyi en çok kirleten maddelerden birisi de boyar ham maddelerdir. Boyarmaddeler, birçok malzemenin renklendirilmesinde ve yüzey özelliklerinin geliştirilmesinde, ilaç sanayinde (Bazylevich, Patsenker, \& Gellerman, 2017), dye lazerlerde elektro optik manyetik 1şımanın dalga boyunu ayarlamada (Cyprych, Kopczyńska, Kajzar, Rau, \& Mysliwiec, 2015), fotodinamik terapide (Kamkaew et al., 2013; Molupe et al., 2018), gida ve kozmetik endüstrisinde (Patil \& Datar, 2016) ve daha birçok alanda geniş kullanıma sahiptir. Endüstride kullanılan boyarmaddelerin birçoğu sentetiktir ve toksik etkisi, ciddi çevre ve sağlık sorunlarına yol açmaktadır. Dolayısıyla, üretim ve tüketim aşamalarında atık sulara bırakılan boyarmaddelerin giderimi önemli bir sorun haline gelmiştir. $\mathrm{Bu}$ sorunların üstesinden gelebilmek için bilim insanları birçok yöntem geliştirmişlerdir. Bunlardan 1sitma, oksidasyon, çöktürme ve biyolojik bozunmaya bırakılma gibi yöntemlere çok az boyar madde cevap verebilmektedir. Doğal ve biyo-bozunur olmayan boyar maddelerin gideriminde ağırlıklı olarak adsorpsiyon yöntemi kullanılmaktadır (Bai et al., 2016; Shak, Dawood, \& Sen, 2017). Sulu ortamdan boyarmaddelerin fiziksel ya da kimyasal olarak adsorpsiyonu, gerek sürecin kolayca takip edilebilmesi ve maliyeti, gerekse boyarmaddelerin \%90-99 oranlarına kadar uzaklaştırılabilmeleri açısından ileri düzeyde etkin bir yöntemdir ve araştırmacılar arasında oldukça ilgi çekicidir (Al-Ghouti, Khraisheh, Allen, \& Ahmad, 2003; Lin, Ma, Liu, Li, \& He, 2019; Raj, Manimozhi, \& Saravanathamizhan, 2019; Zhou, Zhou, Hu, Yan, \& Yang, 2019).

Yapılan birçok çalışmada çevre temizliği ve insan sağlığının odak noktası olması sebebiyle, adsorpsiyon çalışmalarında biyobozunur, çevreye ve insan sağlığına olumsuz etkisi bulunmayan adsorbanların kullanımı önemli hale gelmiştir. Son zamanlarda çevre kirleticilerin uzaklaştırılmasında en çok kullanılan malzemeler biyo-kütle adı verilen zirai ve evsel atıklardır (Moghazy, 2019; Oymak \& Eruygur, 2019; Rapo, Szep, Keresztesi, Suciu, \& Tonk, 2018; Sharma, Hasan, Kumar, \& Pandey, 2018). Çevre-dostu ve düşük maliyetli olmaları sebebiyle biyoatıkların kullanımı hızla yaygınlaşmakta ve birçok sentetik malzemenin yerini almaktadır. Özellikle çeşitli hasat dönemleri sonunda budama atığı olarak çevreye bırakılan, yakılma veya gübre olarak değerlendirilen zirai atıkların, boyar madde gideriminde son derece etkili oldukları ortaya çıkarılmıştır (Dai et al., 2018; Singh, Chauhan, Jain, \& Sharma, 2017; Subramaniam \& Ponnusamy, 2015). Boyar maddeler gibi çeşitli kirleticilerin giderilmesinde çevreye duyarlı bu biyo-kütle kaynaklarının kullanılmaları nedeniyle, adsorpsiyon yöntemleri bilim insanları tarafindan genellikle "biyosorpsiyon" adı altında irdelenmiștir (Akar, Celik, Tunc, Balk, \& Akar, 2016; Kaushik, Mishra, Malik, \& Pant, 2014; Ponnusami, Kumar, \& Bansal, 2018).

$\mathrm{Bu}$ çalışmada, Türkiye-Doğu Karadeniz bölgesinde önemli bir tarım ürünü olan çay bitkisinin "çay çalısı” adı verilen budama atıkları kullanılarak, Eosin Y (EY) boyarmaddesinin sulu ortamdan 
uzaklaştırılması hedeflendi. Bu amaçla, atık çay çalısının çeşitli saflaştırma işlemleri ile bir biyosorbente (adsorban) dönüşümü ve EY ile elektrostatik olarak etkileşime girerek adsorplanması sağlandı. Biyosorbent kaynağı olarak yaş çay üretiminde verimden düşmüş çay bitkisinin dal, odunsu gövde gibi kısımlarının budanması sonucu ortaya çıkan çalı kısımları kullanılmıştır. Biyosorpsiyon çalışmasında, başlangıç boyarmadde konsantrasyonu, $\mathrm{pH}$, biyosorbent miktarı ve

\section{Materyal ve Metot}

\subsection{Kullanılan Kimyasal Maddeler}

Atık sulardan boyarmadde giderimi için model boya olarak Merck firmasından satın alınan Eosin Y (EY) bileşiği, herhangi bir ön saflaştırma işlemi yapılmadan kullanıldı. Molekülün kimyasal formülü, Şekil l'de sunulmuştur. Boya giderimi için Türkiye Rize ili çay veriminden düşmüş çay çalısı budama atıkları çeşitli ögütme, eleme ve saflaştırma basamaklarından geçirilerek kullanıldı. Ayrıca çay çalısının yıkanması için deiyonize saf su kullanılmıştır.<smiles>[M]Oc1c(Br)cc2c(-c3ccccc3C(=O)OC)c3cc(Br)c(=O)c(Br)c-3oc2c1Br</smiles>

Şekil 1. EY molekülün kimyasal yapısı

Eğer çalışma deneysel ise kullanılan deneysel yöntemler detaylı ve açıklayıcı bir biçimde verilmelidir. Çalışmada kullanılan metot, başkaları tarafından tekrarlanabilecek şekilde açıklayıcı olmalıdır. sıcaklık gibi parametrelerin yanı sıra, deneysel veriler ışı̆̆ında adsorpsiyon izotermleri ve termodinamiği de belirlenmiştir. Ayrıca, saf çay çalısının EY ile etkileşimi sonucunda yüzey fonksiyonel gruplarının ve morfolojik özelliklerinin ne şekilde değiştiğinin gösterilmesi adına, fourier dönüşümlü kızıl-ötesi spektroskopisi (FT-IR) ve taramalı elektron mikroskopisi (SEM) yöntemleri kullanılmıştır.

\subsection{Analiz ve Deneysel Yöntemler}

Bir adsorban olarak kullanılan biyo-atık ürünün (çay çalısı), suda çözünür inorganik safsızlıklarını gidermek için deiyonize su altında yoğun bir şekilde yıkanması sağlandı. Sonra, 24 saat boyunca $105^{\circ} \mathrm{C}^{\prime}$ da etüvde kurutuldu. Biyo-atık malzemenin talaş haline getirilebilmesi için ürün öncelikle öğütücüde parçaland 1 ve daha sonra çeşitli elek boyutlarında elenmiştir. Daha sonra, partikül boyutu sadece $75 \mu$ m'den daha küçük olan (optimum değer) örnekler kullanılmıştır. Küçük partikül boyutu, adsorpsiyon bölgelerinde ve adsorbentin toplam yüzey alanında bir artışa neden olması sebebiyle tercih edilmiştir. Deiyonize suda 0,692 g.L $\mathrm{L}^{-1}$ $\left(1,0 \times 10^{-3} \mathrm{M}\right)$ EY bileşiği için stok çözelti hazırland1. Daha sonra, optimum konsantrasyonlar göz önüne alınarak stok çözelti seyreltildi ve farklı derişimlerdeki EY bileşiğinin UV-Vis bölgede $517 \mathrm{~nm}$ dalga boyunda elde edilen maksimum absorbans değerleri ile standart kalibrasyon grafiği çizildi. Sulu çözeltiden boyarmadde adsorpsiyonu çalışmaları için ise yaklaşık olarak 2,0-5,0 mg. $\mathrm{L}^{-1}$ aralığında 7 farklı konsantrasyon örneği seçildi.

Çalkalayıcılı su banyosunda adsorbat (EY) ve adsorbanın (çay çalısı) etkileşmesi sağlanarak, adsorpsiyon çalışmalarında, 
temas süresinin etkisi, önceden belirlenmiş zaman aralıklarında çalkalayıcıdan numuneler alınarak çalışıldı ve çözeltide adsorplanmadan kalan EY konsantrasyonu analiz edildi. Son olarak, denge adsorpsiyon verilerini belirlemek için Langmuir ve Freundlich izotermleri kullanıldı. Adsorpsiyon testleri için Perkin-Elmer (Model Lambda 35) spektrofotometresi kullanılmıştır. Denge konsantrasyonları $517 \mathrm{~nm}$ 'de $\left(\lambda_{\text {mak }}\right)$ yapılan absorbans ölçüm değerleri kullanılarak standart kalibrasyon grafiği yardımıyla belirlendi. Biyo-kütle-boyarmadde sulu süspansiyonları, istenen konsantrasyonlarda $10.0 \mathrm{~mL}$ sulu EY çözeltisine $0.50 \mathrm{~g}$ biyo-kütle eklenecek şekilde hazırlanmıştır. Elde edilen sulu süspansiyonlar plastik bir falkon tüpüne yerleştirildi ve daha sonra bir çalkalayıcıda 25 ${ }^{\circ} \mathrm{C}$ 'de yaklaşık olarak 25 dakika (adsorpsiyon denge süresi) boyunca kuvvetlice karıştırıldı. Daha sonra süspansiyonlar 10.000 rpm'de 10 dakika santrifüj edildi. Denge anında birim adsorbanın kütlesi başına adsorbe edilen EY miktarı, $q_{\mathrm{d}}\left(\mathrm{mg} \cdot \mathrm{g}^{-1}\right)$, eşitlik 1'de gösterildiği şekilde hesapland1;

$$
q_{d}=\frac{\left(C_{0}-C_{d}\right) \cdot V}{W}
$$

Burada, $C_{0}$ ve $C_{d}\left(\mathrm{mg} . \mathrm{L}^{-1}\right)$, sırasıyla başlangıç ve denge anındaki EY bileşiğinin konsantrasyonlarına karşılık gelmektedir. V (L), çözelti hacmini, W (g) ise adsorbanın kütlesini belirtmektedir.

\section{Bulgular}

\subsection{Etkileşim Süresi ve Başlangıç EY konsantrasyonunun Adsorpsiyon Üzerine Etkisi}

Optimum EY konsantrasyonunu ve denge süresini belirlemek için, farklı başlangıç konsantrasyonları kullanıldı ve maksimum adsorpsiyona ulaşılıncaya kadar zaman aralıkları değerlendirildi. Şekil 2'de, denge süresine gelinceye kadar, $0,5 \mathrm{~g}$ biyosorbentin çeşitli başlangıç konsantrasyonlarında EY bileşiğini sulu çözeltiden adsorplama miktarı $25^{\circ} \mathrm{C}$ da ve $\mathrm{pH} 7.0^{\prime} \mathrm{da}$ gösterilmiştir. Denge anında birim adsorban başına maksimum adsorbe edilmiş EY miktarı (mg/g), 2,0-4,0 ve $5,0 \quad \mathrm{mg} / \mathrm{L}$ boyarmadde başlangıç konsantrasyonlarında sirasıyla, 3,83 mg/g (\% 95 boya giderimi), $6,77 \mathrm{mg} / \mathrm{g}$ (\% 84 boya giderimi) ve $7,73 \mathrm{mg} / \mathrm{g}$ (\%77 boya giderimi) olarak ölçüldü. Boyarmadde giderimi yüzdesinin, başlangıç konsantrasyonu arttıkça azaldığı Şekil 2'de açıkça görülmektedir. EY için denge süresinin $2,0 \mathrm{mg} / \mathrm{L}$ için yaklaşık 22 dakika, $5,0 \mathrm{mg} / \mathrm{L}$ için yaklaşık 25 dakika ve $10,0 \mathrm{mg} / \mathrm{L}$ için yaklaşık 23 dakika olduğu bulundu. Ayrica adsorpsiyonun ilk aşamalarda hızlı olduğu ve zamanla yavaşlayarak sabit kaldığı görülmektedir. \% boyarmadde giderimi oranlarına (\%77 95) bakıldığında atık çay çalısının etkili bir adsorban olduğu kabul edilebilir. 


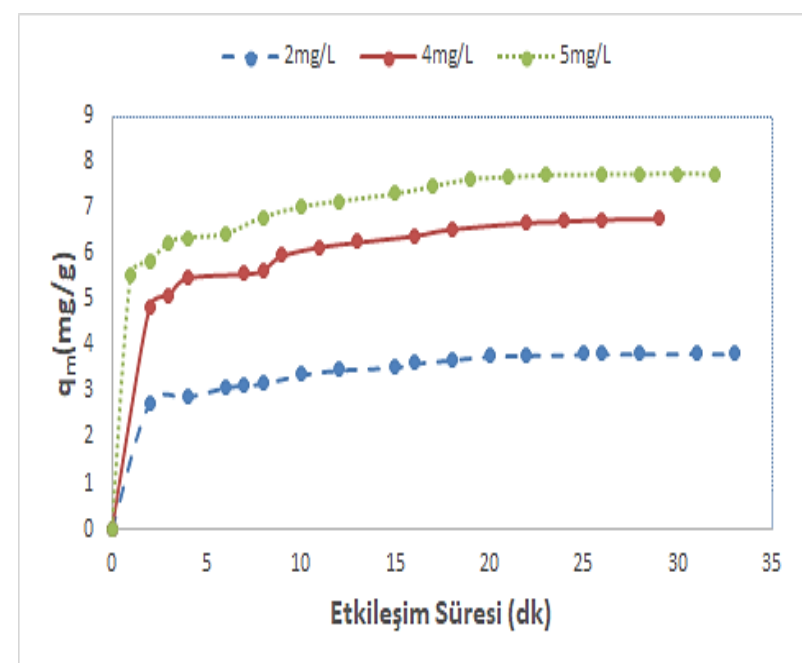

Şekil 2. Adsorpsiyon Üzerine Başlangıç Konsatrasyonu ve Zamanın Etkisi

\subsection{Adsorpisyon Üzerine pH Etkisi}

EY çözeltisinin $\mathrm{pH}$ düzeyinin adsorpsiyon üzerindeki etkisi aşağıdaki prosedüre göre incelenmiştir. $50 \mathrm{ml}$ EY çözeltisi $(10,0 \mathrm{mg} / \mathrm{L})$ içeren bir dizi plastik tüpe $0,50 \mathrm{~g}(-75 \mu \mathrm{m}$ partikül boyutu) biyosorbent eklendi. Boya çözeltilerinin $\mathrm{pH}$ değeri, her tüp için $0,1 \mathrm{M}$ $\mathrm{HC} 1$ veya $0,1 \quad \mathrm{M} \quad \mathrm{NaOH}$ çözeltileri kullanılarak pH 2-11 aralığında ayarlandı. Tüpler kapatıld 1 ve 5 saat boyunca $25 \pm 1^{\circ}$ C'da çalkalayıcıya yerleştirildi. Boya giderimi üzerinde $\mathrm{pH}$ nın etkisi, Şekil 3'de sunulmuştur. Şekle bakıldığında, asidik pH dan $\mathrm{pH}=7$ ye kadar $\%$ adsorplanan madde miktarında $(\approx \% 90)$ kayda değer bir değişim gözlenmemiştir. Ortam bazikliği artırıldığında, yani $\mathrm{pH}$ yükseltildiğinde adsorplanan EY yüzdesinin önemli ölçüde düştüğü Şekil 3'ten çıkarılabilir. Mevcut durumda, biyosorbentin nötr bir yük yapısına sahip olduğu özellikle bazik pH lara kadar boyarmaddenin elektrostatik özelliğinden etkilenmediği düşünülebilir. Nötral $\mathrm{pH}$ dan sonra negatif yük yoğunluğuna sahip EY bileşiğinin artan $\mathrm{pH}$ etkisiyle biyosorbente tutunma afinitesini önemli derecede kaybettiği söylenebilir.

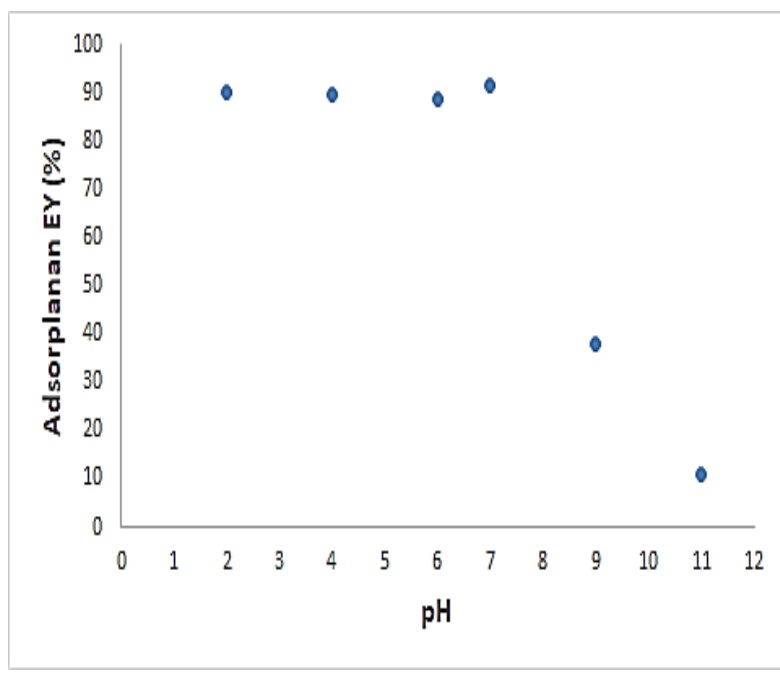

Şekil 3. Adsorplanan \% EY Üzerine pH Etkisi

\subsection{Adsorban Miktarının Adsorpsiyon Üzerine Etkisi}

Başlangıçta 10,0 mg/L konsantrasyona sahip EY çözeltisi hazırlandı. $50 \mathrm{~mL}$ çözelti içerisine $-75 \mu \mathrm{m}$ partikül boyutlu, $0,01, \mathrm{~g}$, $0,025 \mathrm{~g}, 0,05 \mathrm{~g}, 0,075 \mathrm{~g}, 0,10 \mathrm{~g}, 0,25$ ve $0,5 \mathrm{~g}$ kütlelere sahip adsorban plastik falkon tüplerine yerleştirildi. Tüpler kapatıldı ve 2 saat boyunca $25 \pm 1{ }^{\circ} \mathrm{C}^{\prime}$ da çalkalayıcıda muamele edildi. İki saat sonra, adsorbe edilen boyarmadde miktarları (mg/g) belirlendi. Şekil4'te adsorbe edilen boyarmadde miktarının adsorban miktarı ile değişimi verilmiştir. Şekil 4'de görüldüğü gibi, adsorbe edilmiş EY miktarı, 0,25 g adsorban miktarında maksimum seviyeye ulaşmış ve daha sonra adsorban miktarı arttırılsa bile değişmemiştir. Böylece optimum adsorban miktarı yaklaşı olarak 0,25 g olarak belirlenmiştir. 


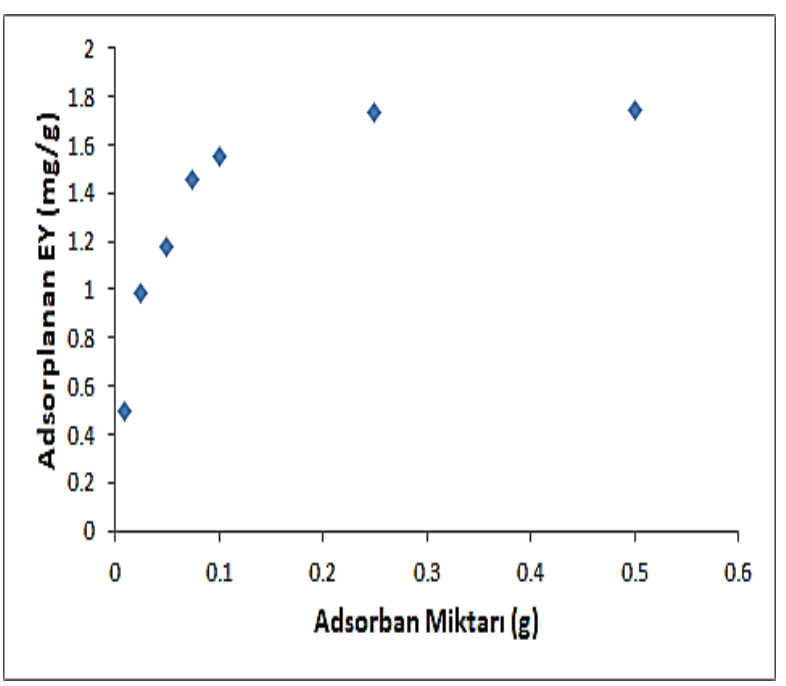

Şekil 4. Adsorplanan EY Miktarı Üzerine Adsorban Miktarı Etkisi

\subsection{Adsorpsiyon İzotermleri}

EY bileşiğinin bir biyo-atık olan çay çalısı (biyosorbent-adsorban) ile etkileşiminin, deneysel verilerin matematiksel eşitliklerle açıklanabilmesi açısından adsorpsiyon izotermleri önem arz etmektedir. Ayrica adsorbanın adsorpsiyon kapasitesi tabakalaşma yapısı vb. bilgiler hakkında da fikir verir. Etkileşim sonucunda yüzey fazı, tek katmanlı veya çok katmanlı olarak kabul edilebilir. Bu amaç için, Freundlich [(Eşitlik 2)] ve Langmuir [Eşitlik (3)] eşitlikleri deneysel verilere uygulanarak izoterm grafikleri çizilmiştir.

$$
\begin{aligned}
& \log q_{d}=\log K_{f}+\frac{1}{n} \log C_{d} \\
& \frac{C_{d}}{q_{d}}=\frac{C_{d}}{q_{m}}+\frac{1}{K_{L} \cdot q_{m}}
\end{aligned}
$$

burada $K_{f}$ ve n, sirasiyla adsorpsiyon kapasitesini ve adsorpsiyon yoğunluğunu gösteren Freundlich sabitleridir. $C_{d}$, tutunmadan kalan boyarmaddenin denge konsantrasyonudur (mg. $\mathrm{L}^{-}{ }^{1}$ ) ve $q_{d}$, adsorbanın (g) birim kütlesi başına adsorbe edilen (mg) EY miktarıdır. Biyosorbent üzerine EY adsorpsiyonu durumunda, n ve $K_{f}$ sabitleri için deneysel değerler sırasıyla, 1,612 ve 0,578 olarak bulundu. "n" değeri 1 ile 10 aralığında bir değer aldığında iyi bir adsorpsiyon potansiyelinin olduğunu göstermektedir (Errais et al., 2011). Langmuir adsorpsiyon izotermi verilerine bakıldı ğında, maksimum adsorpsiyon kapasitesi $\mathrm{q}_{m}(3,56$ $\mathrm{mg}^{-1}$ ) ve tek tabak tabaka adsorpsiyon enerjisi ile ilgili bir sabit olan $K_{L}\left(0,157 \mathrm{Lg}^{-1}\right)$ olarak bulunmuştur. Şekil 5'te izotermler, Tablo 1'de ise bu izotermlere ait deneysel veriler gösterilmiştir.
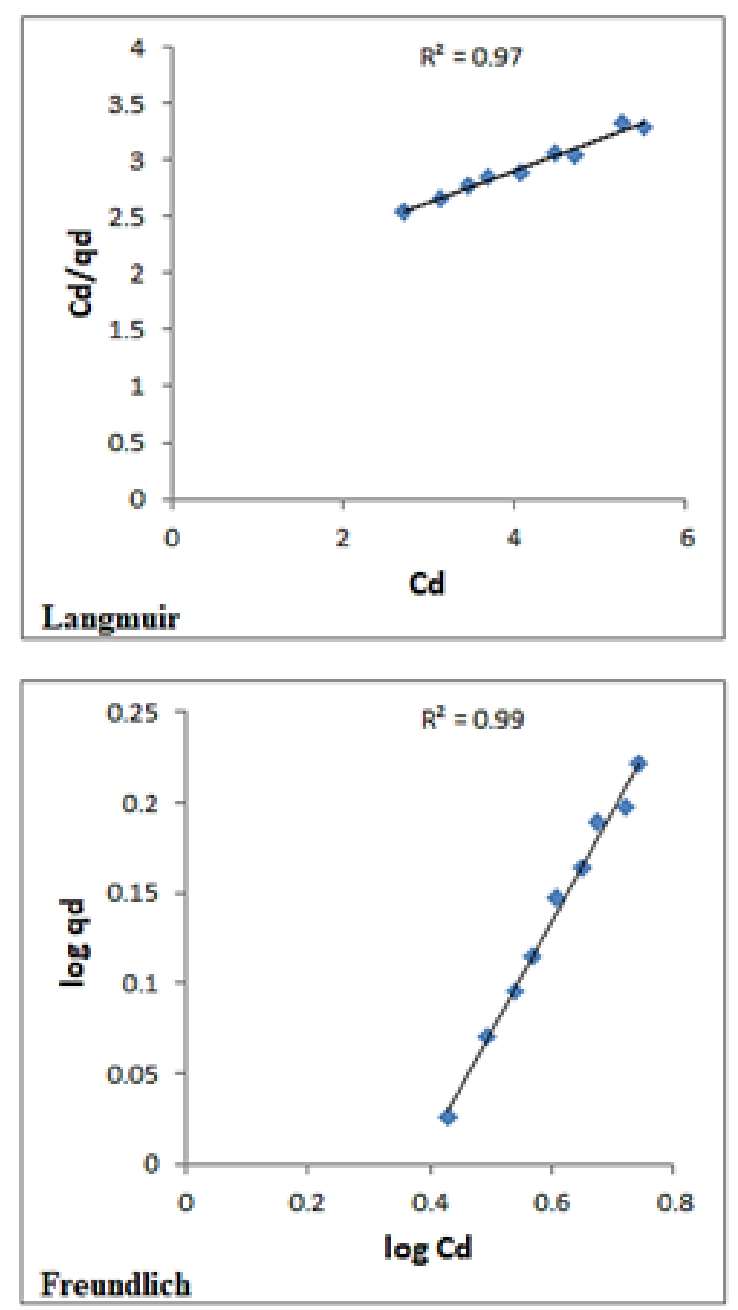

Şekil 5. Langmuir ve Freundlich Adsorpsiyon İzoterm Grafikleri 
Tablo 1. Adsorpsiyon İzotermlerinin Deneysel Sonuçları

\begin{tabular}{|c|c|c|c|c|c|c|}
\hline $\begin{array}{l}\text { Boyar } \\
\text { madde }\end{array}$ & Lang & nuir & & reundli & & \\
\hline \multirow{2}{*}{ EY } & $\mathbf{q}_{m}$ & $\mathrm{~K}_{L}$ & $\mathrm{R}^{2}$ & $\mathrm{n}$ & $\mathrm{K}_{f}$ & $\mathrm{R}^{2}$ \\
\hline & 3,56 & 0,157 & 0,97 & 0,578 & 1,612 & 0,99 \\
\hline
\end{tabular}

Verilere dikkat edildiğinde deneysel sonuçların Freundlich İzotermi ile daha fazla uyum sağladığı görülmektedir. Şekil 5'de Langmuir ve Freundlich izotermlerine ait grafikler gözükmektedir. Buna ilaveten, Tablo 1'deki sonuçlara dikkat edildiğinde bu çalışmadaki adsorpsiyon sistemine hangi izoterm modelinin daha fazla uygunluk gösterdiği açıkça görülmektedir.

\section{Sonuç}

$\mathrm{Bu}$ çalışma, doğal olarak elde edilebilen bir biyosorbent olan atık çay çalısı (adsorban) kullanılarak, EY'nin sulu çözeltiden uzaklaştırılması üzerine klasik adsorpsiyon deney yöntemleri kullanılarak gerçekleştirildi. Temas süresi, başlangıç adsorbat konsantrasyonu ve adsorban miktarı gibi operasyonel parametrelerin boyarmadde giderim verimliliği üzerinde önemli bir etkisi olduğu anlaşıldı. Çalışmada, Langmuir ve Freundlich izoterm modelleri gibi adsorpsiyon denge modelleri kullanılmıştır. Elde edilen sonuçlar, EY'nin çay çalısı adsorbanına adsorpsiyon işleminin, Freundlich izoterm modeli ile daha fazla uygunluk gösterdiğini ortaya koymuştur. Mevcut çalı̧̧ma, boyarmadde giderimi oranları izoterm verileri gibi parametreler dikkate alındığında, çay çalısının anyonik bir bileşik olan EY'nin atık sulardan uzaklaştırılması için etkili bir adsorban olarak kullanılabileceğini göstermektedir. $\mathrm{Bu}$ çalışmada EY bileşiğinin adsorplanması amaciyla yerel bir biyokütle kaynağı olan atık çay çalısı ilk kez kullanılmıştır. Doğal bir hammaddenin değerlendirilmesi ve bu hammaddenin çevreyi kirletici bileşenlerin uzaklaştırılmasında "Yeşil Kimya" çerçevesinde kalarak yol gösterici olması açısından, bu çalışmanın bu alandaki bilimsel literatüre 1şık tutabileceği düşünülmektedir.

\section{Kaynaklar}

Akar, S. T., Celik, S., Tunc, D., Balk, Y. Y., \& Akar, T. (2016). Biosorption potential of surface-modified waste sugar beet pulp for the removal of Reactive Yellow 2 (RY2) anionic dye. Turkish Journal of Chemistry, 40(6), 1044-1054.

Al-Ghouti, M. A., Khraisheh, M. A. M., Allen, S. J., \& Ahmad, M. N. (2003). The removal of dyes from textile wastewater: a study of the physical characteristics and adsorption mechanisms of diatomaceous earth. Journal of Environmental Management, 69(3), 229-238.

Bai, H. H., Zhang, Q. S., He, T., Zheng, G., Zhang, G. Q., Zheng, L. B., \& Ma, S. Q. (2016). Adsorption dynamics, diffusion and 
isotherm models of poly(NIPAm/LMSH) nanocomposite hydrogels for the removal of anionic dye Amaranth from an aqueous solution. Applied Clay Science, 124, 157-166.

Bazylevich, A., Patsenker, L. D., \& Gellerman, G. (2017). Exploiting fluorescein based drug conjugates for fluorescent monitoring in drug delivery. Dyes and Pigments, 139, 460-472.

Cyprych, K., Kopczyńska, Z., Kajzar, F., Rau, I., \& Mysliwiec, J. (2015). Tunable wavelength light emission and amplification in Rhodamine 6G aggregates. Advanced Device Materials, 1(2), 69-73.

Dai, Y., Sun, Q., Wang, W., Lu, L., Liu, M., Li, J., . . . Xu, J. (2018). Utilizations of agricultural waste as adsorbent for the removal of contaminants: A review. Chemosphere.

Errais, E., Duplay, J., Darragi, F., M'Rabet, I., Aubert, A., Huber, F., \& Morvan, G. (2011). Efficient anionic dye adsorption on natural untreated clay: Kinetic study and thermodynamic parameters. Desalination, 275(1-3), 74-81.

Kamkaew, A., Lim, S. H., Lee, H. B., Kiew, L. V., Chung, L. Y., \& Burgess, K. (2013). BODIPY dyes in photodynamic therapy. Chemical Society Reviews, 42(1), 77-88.

Kaushik, P., Mishra, A., Malik, A., \& Pant, K. K. (2014). Biosorption of Textile Dye by Aspergillus lentulus Pellets: Process Optimization and Cyclic Removal in Aerated Bioreactor. Water Air and Soil Pollution, 225(6).

Lin, Y. C., Ma, J., Liu, W., Li, Z. Y., \& He, K. (2019). Efficient removal of dyes from dyeing wastewater by powder activated charcoal/titanate nanotube nanocomposites: adsorption and photoregeneration. Environmental Science and Pollution Research, 26(10), 10263-10273.

Moghazy, R. M. (2019). Activated biomass of the green microalga Chlamydomonas variabilis as an efficient biosorbent to remove methylene blue dye from aqueous solutions. Water Sa, 45(1), 20-28.

Molupe, N., Babu, B., Oluwole, D. O., Prinsloo, E., Mack, J., \& Nyokong, T. (2018). The investigation of in vitro dark cytotoxicity and photodynamic therapy effect of a 2,6dibromo-3,5-distyryl BODIPY dye encapsulated in Pluronic (R) F-127 micelles. Journal of Coordination Chemistry, 71(21), 3444-3457.

Oymak, T., \& Eruygur, N. (2019). Effective and rapid removal of cationic and anionic dyes from aqueous solutions using Elaeagnus angustifolia L. fruits as a biosorbent. Desalination and Water Treatment, 138, 257264.

Patil, N. N., \& Datar, A. G. (2016). Applications of natural dye from Ixora coccinea $\mathrm{L}$. in the field of textiles and cosmetics. Coloration Technology, 132(1), 98-103.

Ponnusami, A. B., Kumar, S., \& Bansal, P. (2018). Biosorption and kinetic studies of Malachite Green (MG) dye removal from aqueous solution using a low-cost adsorbent prepared from male palm tree flower (Borassus flabellifer). Desalination and Water Treatment, 121, 219-232.

Raj, R. A., Manimozhi, V., \& Saravanathamizhan, R. (2019). Adsorption studies on removal of Congo red dye from aqueous solution using petroleum coke. 
Petroleum Science and Technology, 37(8), 913-924.

Rapo, E., Szep, R., Keresztesi, A., Suciu, M., \& Tonk, S. (2018). Adsorptive Removal of Cationic and Anionic Dyes from Aqueous Solutions by Using Eggshell Household Waste as Biosorbent. Acta Chimica Slovenica, 65(3), 709-717.

Shak, A., Dawood, S., \& Sen, T. K. (2017). Performance and dynamic modelling of mixed biomass-kaolin packed bed adsorption column for the removal of aqueous phase methylene blue (MB) dye. Desalination and Water Treatment, 82, 67-80.

Sharma, S., Hasan, A., Kumar, N., \& Pandey, L. M. (2018). Removal of methylene blue dye from aqueous solution using immobilized Agrobacterium fabrum biomass along with iron oxide nanoparticles as biosorbent. Environmental Science and Pollution Research, 25(22), 21605-21615.

Singh, H., Chauhan, G., Jain, A. K., \& Sharma, S. (2017). Adsorptive potential of agricultural wastes for removal of dyes from aqueous solutions. Journal of environmental chemical engineering, 5(1), 122-135.

Subramaniam, R., \& Ponnusamy, S. K. (2015). Novel adsorbent from agricultural waste (cashew NUT shell) for methylene blue dye removal: optimization by response surface methodology. Water Resources and Industry, 11, 64-70.

Zhou, L., Zhou, H. J., Hu, Y. X., Yan, S., \& Yang, J. L. (2019). Adsorption removal of cationic dyes from aqueous solutions using ceramic adsorbents prepared from industrial waste coal gangue. Journal of Environmental Management, 234, 245-252. 